\title{
RUPTURE OF A MYCOTIC ANEURYSM OF THE THORACIC AORTA
}

\author{
BY \\ S. N. JAVETT and E. KAHN \\ From the Transvaal Memorial Hospital for Children, Johannesburg
}

(RECEIVED FOR PUBLICATION OCTOBER 1, 1951)

Aortic aneurysms are rare in childhood. Calvin and Nichamin (1934), in a review of the literature up to 1934 were able to find 44 cases under the age of 18 years. They added two cases of their own. Since this time seven further cases have been reported bringing the total to 53 cases. The patient to be described was first seen 18 months before death and was suffering from streptococcal septicaemia. At that time a radiograph of the chest was normal. The fatal haemoptysis terminating the second admission to hospital occurred from an aortic aneurysm which presumably developed as a consequence of the initial illness.

\section{Case Report}

The patient, a girl aged 13 months, was admitted to hospital on October 12,1948, with a history of feverishness and fretfulness for one month. The day before admission she suddenly became worse, was unable to sit up, manifested pain in the legs when the napkin was changed and ran a high temperature. On examination the child appeared ill. She was irritable, resented handling, and the neck was resistive to flexion. A spotty, purpuric rash was present all over the body, more marked on the buttocks. The temperature was $104^{\circ} \mathrm{F}$., pulse rate 150 . The heart sounds were closed, and râles were present at both bases. The right knee joint was red, swollen and tender. A presumptive diagnosis of septicaemia with complicating arthritis and meningitis was made.

Laboratory Studies. A blood count on October 12 gave the following results: Haemoglobin, $9 \cdot 4 \%$; colour index, 0.92; red cells, 3,290,000; white cells, 19,300 (neutrophils $77 \%$, monocytes $2 \%$, lymphocytes $19 \%$, plasma cells $1 \%$, metamyelocytes $1 \%$ ). The red cells showed anisocytosis and polychromasia. Some polymorphs showed toxic granulation and there was a slight shift to the left.

The cerebrospinal fluid was examined on October 12, and showed 22 polymorphs, 5 lymphocytes and one disintegrated cell per c.mm. No bacteria were detected on direct or cultural examination. Total protein was $35 \mathrm{mg} . \%$, chloride $715 \mathrm{mg} \%$ and sugar $63 \mathrm{mg} . \%$. Three days later the examination was repeated and 2 polymorphs and 2 lymphocytes per c.mm. were present. Occasional erythrocytes were seen. No bacteria were found on direct and cultural examination. Total protein was $40 \mathrm{mg} .{ }^{\circ}, 0$, chlorides $725 \mathrm{mg} .{ }^{\circ} \circ$ and sugar $60 \mathrm{mg} .{ }^{\circ}$.

Blood culture on October 12 recovered a nonhaemolytic streptococcus.

Agglutination tests for typhoid and paratyphoid were negative on October 14.

A radiograph of the chest on October 13 (Fig. 1)

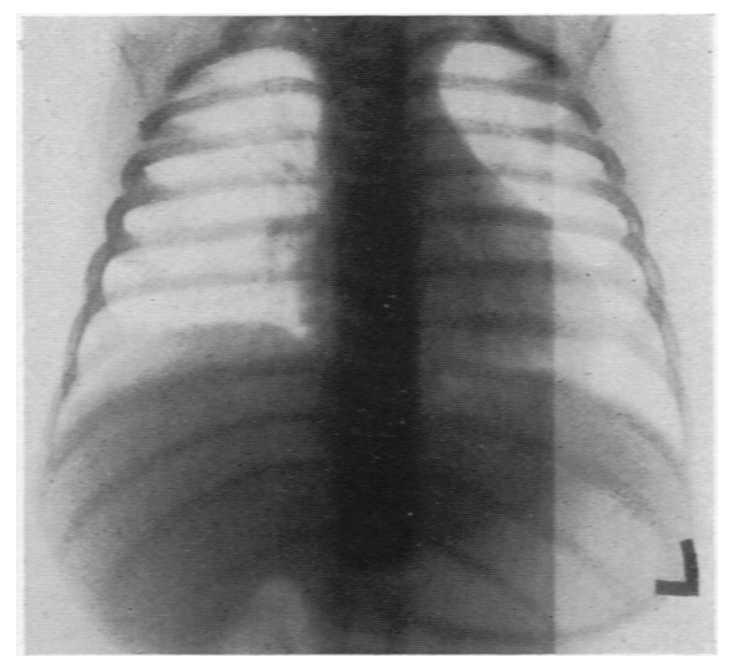

Fig. 1. Radiograph on the first admission showing a normal heart with no evidence of aneurysm.

showed that the lungs and heart were normal. The Mantoux test was negative.

The child was treated with penicillin, 50,000 units intramuscularly every three hours, with one sulphadiazine tablet, at the same time and half a tablet every four hours. Penicillin, 10,000 units, was given intrathecally on October 16.

The temperature subsided within three days and the child was discharged 10 days after admission. The final diagnosis was streptococcal septicaemia.

The child was re-admitted to hospital on April 24, 1950, at the age of 2 years and 7 months, with a history of having coughed up 2-3 oz. of bright red, frothy blood the previous day. She had been in good health since the previous admission except for frequent attacks of 'bronchitis'. The haemoptysis had occurred without warning and was followed a few hours later by a small haematemesis of presumably swallowed blood. 


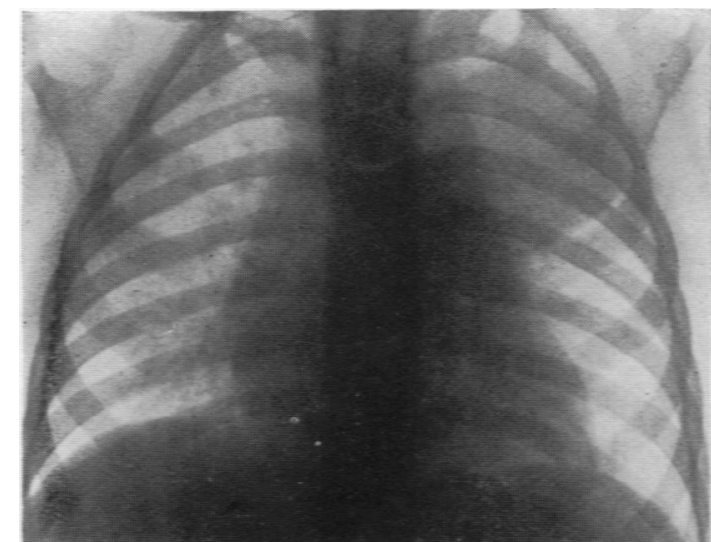

Fig. 2.-Aneurysm of arch of aorta. coarse crepitations and râles, and the systolic murmur could only be heard anteriorly over the left apex of the lung. On the following morning the child suddenly coughed up a large amount of blood, estimated at several pints, and died within a few minutes.

The following investigations had been carried out after admission: The Mantoux test was negative at $1: 1,000$. The prothrombin index was $97^{\circ}$ of normal. A blood count gave haemoglobin $11 \cdot 2^{\circ}$; colour index, 0.95 ; red cells, $3,820,000$; total white cells, 19,600 per c.mm.: packed cell volume, $33 \cdot 5^{\circ} . \circ$; sedimentation rate $30 \mathrm{~mm}$. in one hour.

The stools contained cysts of Giardia intestinalis.

Necropsy. The upper lobe and the upper portion of the lower lobe of the left lung were bound to the posterior thoracic wall by dense, avascular adhesions. Similar adhesions had obliterated the fissure between the left upper and lower lobes. At the apex of the left upper lobe there were some bullous areas which were filled with blood. The rest of the heart and of the lungs was normal on inspection. In the substance of the apex of the left upper lobe, and extending a little into the apex of the lower lobe, a hard, round mass was palpable. This mass was completely surrounded by lung tissue and the dense adhesions just mentioned which glued together the two lobes of the lung. An incision through the apex into the mass (Fig. 4) showed an aneurysm, 1 in. in diameter, which was found to arise from the convexity of the aortic arch, just distal to the origin of the left subclavian artery, the communication being a clean, round hole $2 \mathrm{~mm}$. in diameter. The interior of the aneurysm in the immediate vicinity of the opening into the aorta was covered by normal endothelium. The opposite wall consisted of concentric layers of avascular, organized clot. One portion of the upper wall, which was covered with fresh, ante-mortem clot, had given way and the aneurysm had ruptured into one of the bronchi of the left upper lobe.

The heart was macroscopically normal. There was no evidence of endocarditis. Microscopic sections of the aorta in the region of the aneurysm showed replacement of muscle and elastic tissue by hyaline fibrous tissue (scar tissue). There were no signs of active inflammation or of rheumatic aortitis. The histological features of the sections were thought to be consistent with the diagnosis of old mycotic aneurysm.

Sections of the heart muscle showed no abnormalities. clear on auscultation, except for some coarse crepitations at the left apex. In addition, a fairly loud, blowing. systolic murmur was audible widely over the upper part of the chest on the left side, posteriorly as well as anteriorly. The heart sounds were closed at the apex. Radiographs (Figs. 2 and 3) taken on the previous day showed an opacity with a sharply defined lower edge at the apex of the left lung. This opacity had not been present when the child was radiographed in 1948 during her first stay in hospital. The diagnosis of an angiomatous tumour was mooted and fluoroscopic screening was to be carried out the following morning to define the limits of the mass in the left apex more clearly. However, on the same afternoon, again without any warning, the child coughed up 4-5 oz. of bright red blood.

After the haemoptysis the chest was again filled with 
macroscopically or microscopically, in the aorta and the heart. The aneurysm was not found in the situation of a ductus arteriosus. There were no manifestations of sepsis in the structures adjacent to the aorta, which might have led to its erosion. Finally, there was no sign of endocarditis.

Bronson and Sutherland (1918) quote the following aetiological factors in aneurysm formation in childhood: (1) atheromatous degeneration, (2) trauma, (3) erosion of the aorta from without, (4) congenital malformation, (5) acute infectious diseases. They consider the last group to be the most important one.

Calvin and Nichamin (1934) state that in their series of 44 cases there was ' an association with endocarditis in 10 , and with rheumatic fever in 11 instances'. They continue:

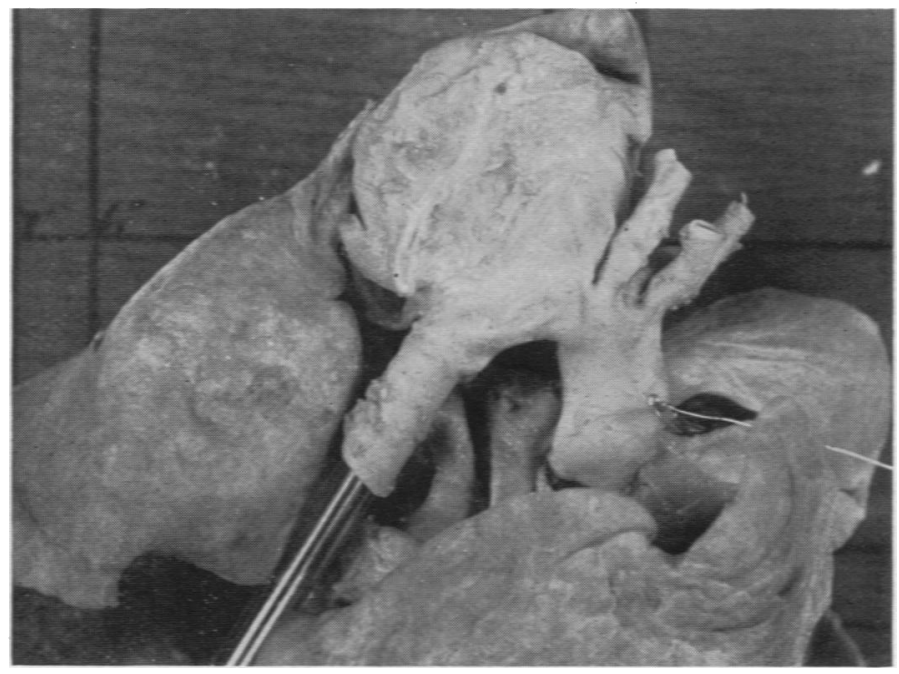

FiG. 4.-Necropsy specimen showing ancurysm 1 in. in diameter.

endocarditis, are very rare indeed. Revell (1945), when discussing this type of aneurysm occurring in any of the arteries and at all ages, was able to list only 23 reports in the medical literature. To these he added a case of his own. The youngest patient was $10 \frac{1}{2}$ years old. This type of aneurysm, rare though it is, seems to have a definite predilection for the thoracic aorta. In 11 of the cases the ascending aorta was the seat of the aneurysm. The arch was involved in five cases and the descending aorta in two cases. The abdominal aorta was affected five times and other arteries in the body seven times. In six cases two or more aneurysms were present in the same individual.

\section{Summary}

Fatal haemorrhage occurred in a child aged 2 years and 7 months from the rupture of an aneurysm of the aortic arch, probably mycotic in origin, into a bronchus of the left upper lobe of the lung. The aetiology of aortic aneurysm in childhood is discussed. The apparent predilection of mycotic aneurysm for the thoracic aorta is pointed out.

\section{Rermences}

Baer, R. W., Taussig, H. B. and Oppenheimer, E. H. (1943). Bull. Johns Hopk. Hosp., $72,309$.

Bronson, E and Sutheriand, G. A. (1918). Brit. J. Child. Dis., 15, 241. Cited by Calvin and Nichamin.

Calvin, J. K, and Nichamin, S. J. (1934). Amer. J. Dis. Child., 48. 780 .

McLaurin, J. W. (1945), New Orleans med. surg. J., 97, 317

Nicolson, G. H. B. (1940). Amer. Heart J. 20, 357.

Revell, S. T. R. (1945). Ann. intern. Med., 22, 431. 